\title{
Dissociation Mediates the Relationship between Childhood Maltreatment and Sub-Clinical Psychosis
}

\author{
Charles Lewis Cole BSc, Katherine Newman-Taylor DClinPsy \& Fiona \\ Kennedy DClinPsy
}

To cite this article: Charles Lewis Cole BSc, Katherine Newman-Taylor DClinPsy \& Fiona Kennedy DClinPsy (2016): Dissociation Mediates the Relationship between Childhood Maltreatment and Sub-Clinical Psychosis, Journal of Trauma \& Dissociation, DOI: 10.1080/15299732.2016.1172537

To link to this article: http://dx.doi.org/10.1080/15299732.2016.1172537

Accepted author version posted online: 04 Apr 2016.

Submit your article to this journal $\sqsubset$

山 Article views: 1

Q View related articles $\sqsubset$

View Crossmark data 5 


\title{
Dissociation mediates the relationship between childhood maltreatment and sub-clinical psychosis
}

\author{
Charles Lewis Cole (BSc) \\ University of Southampton, UK \\ Katherine Newman-Taylor (DClinPsy) \\ University of Southampton, UK \\ Fiona Kennedy (DClinPsy) \\ Greenwood Mentors, UK
}

Corresponding author: Katherine Newman-Taylor, Psychology Academic Unit, University of Southampton, Building 44, Highfield, Southampton, SO17 1BJ, UK. Email: knt@ soton.ac.uk.

\begin{abstract}
Over a third of the population report childhood adversity, and these experiences are associated with an increased risk of clinical and sub-clinical psychosis. The reason why some people go on to develop mental health problems and others do not is a key question for study. It has been hypothesised that dissociative processes mediate the relationship between early adversity and psychosis. The current study assessed whether dissociation, and specifically depersonalisation (one component of dissociation), play a mediating role in the relationship between childhood maltreatment and both hallucination-proneness and delusional ideation. The study used a crosssectional design and recruited a student sample to assess these relationships in a non-clinical group. Dissociation mediated the relationship between early maltreatment and both hallucination-proneness and delusional ideation. In terms of specific dissociative processes, depersonalisation did not mediate hallucination-proneness or delusional ideation. Absorption
\end{abstract}


mediated hallucination-proneness; dissociative amnesia (negatively) and absorption mediated delusional ideation. It is likely that dissociation interferes with the encoding of traumatic information in non-clinical as well as clinical groups, and in certain ways. Absorption may be particularly relevant. For some people, traumatic memories may intrude into conscious awareness in adulthood as psychotic-type experience.

Keywords: Childhood adversity, childhood maltreatment, dissociation, depersonalisation, psychosis, hallucination-proneness, delusional ideation

Childhood adversity is defined as "the experience of life events and circumstances which may combine to threaten or challenge healthy development" (Daniel, Wassell, \& Gilligan 2010, p.105). Worldwide prevalence rates indicate that $38.8 \%$ of adults report any form of adversity in childhood, including specific forms of maltreatment: physical abuse (8.0\%), sexual abuse (1.6\%) and neglect (4.4\%) (Kessler et al., 2010). The National Comorbidity Survey (Molnar, Buka, \& Kessler, 2001) suggests that childhood sexual abuse in particular may be more common, with self-reports of $13.5 \%$ for women and $2.5 \%$ for men.

Importantly, all forms of childhood adversity increase the risk of developing a DSM-IV categorised disorder, with adverse experiences involving maladaptive family functioning proving to be particularly strong predictors (Kessler et al., 2010). In their meta-analysis, Varese and colleagues found that exposure to adverse childhood experiences elevates the risk of clinical and sub-clinical psychosis, including hallucinations and delusional ideation, with an odds ratio of 2.8 (Varese et al., 2012). Childhood sexual abuse may be associated with adult hallucinatory 
experiences specifically (Read, Agar, Argyle, \& Aderhold, 2003; Bentall, Wickham, Shevlin, \& Varese, 2012).

Paranoid thinking and hallucinatory experience are common in the general population; $20-30 \%$ of us report mild forms of paranoia such as concerns about social inferiority or criticism (Bebbington et al., 2013) and estimates of voice hearing range from $0.6 \%$ to $84.0 \%$, with a mean of $19.3 \%$ (Beaven, Read \& Cartwright, 2011). This has led to the conceptualization of a continuum of psychosis from mild, transient ideation and perceptual anomalies experienced by many, to more stable persecutory delusions and distressing voices or other hallucinations that interfere with the lives of a minority (e.g. Johns \& van Os, 2001). Distress often distinguishes clinical and non-clinical groups, and so understanding the causes of distress should be prioritised (Freeman, 2007).

Despite evidence for a relationship between early adversity and psychosis, the mechanisms involved remain unclear (Newman-Taylor \& Sambrook, 2013). In the late nineteenth century, Janet defined dissociation as a failure to integrate experiences that should otherwise be associated, in order to reduce an individual's conscious awareness of traumatic stimuli (1889, in van der Hart \& Horst 1989). It is of note that Janet identifies both the process and function of dissociation, which is to reduce awareness of traumatic experience. Janet described 'idées fixes' or traumatic memories, with associated 'vehement emotions,' which result in intrusions when triggered by reminders of the original trauma. Secondary idées fixes, or 'hysterical psychosis' include trauma-related dreams, fantasies or hallucinations, and have since been re-conceptualised as dissociative psychosis (Kennedy \& Kennerley, 2013). Bleuler conceptualised mental 
'splitting' and 'loosening of associations,' as key psychological processes underlying symptoms of schizophrenia. Recent authors argue that he may in fact have been describing forms of dissociation (Moscowitz \& Heim, 2011).

Psychosis has been described as "traumatic in origin and dissociative in kind" (Moskowitz, Read, Farrelly, Rudegeair, \& Williams, 2009, p. 322). This is supported by the link between trauma and dissociation (e.g. Carlson, Dalenberg \& McDade-Montez, 2012; Dalenberg \& Carlson, 2012), and evidence that dissociation mediates the relationship between earlier traumatic events (particularly childhood sexual abuse) and attenuated psychotic experience (Anglin, Polanco-Roman \& Lui, 2015; Varese, Barkus, \& Bentall, 2012), though others have failed to replicate this for delusional ideation (Perona-Garcelan et al., 2012). Distinct forms of dissociation have been conceptualised and may be differentially relevant to the relationship between early maltreatment and psychosis. Depersonalisation is defined as an altered state of consciousness characterised by a sense of detachment and taking an observer perspective of one's body or mental processes (APA, 2013). Absorption is a form of intensively focused attention in which a person becomes immersed in his or her mental imagery (see Dalenberg \& Paulson, 2010). There is some evidence that both depersonalisation and absorption mediate the relationship between early trauma and hallucinatory experience in clinical and non-clinical groups (Perona-Garcelan et al., 2012; Perona-Garcelan et al., 2014). However, the validity of the most commonly used measure of depersonalisation, a sub-scale of the Dissociative Experiences Scale (DES), has been questioned (Sierra \& Berrios, 2000). 
Holmes and colleagues suggest that peri-traumatic detachment interferes with the encoding of traumatic information. For some people, this results in poorly integrated memories of the traumatic event, which may then intrude into conscious awareness as hallucinations (Holmes et al., 2005). This is consistent with Janet's earlier thinking, and comparable to the cognitive model of flashbacks in PTSD described by Ehlers and Clark (2000).

In summary, there is emerging evidence that dissociation (and depersonalisation and absorption specifically), mediate the relationship between early adversity and hallucination-proneness, in clinical groups (Varese, Barkus \& Bentall, 2012; Perona-Garcelan et al., 2012). Non-clinical studies have demonstrated similar outcomes in Spanish university students (Perona-Garcelan et al., 2014) and shown that dissociation may mediate the relationship between traumatic events and attenuated psychotic experiences in young people from Black and Hispanic ethnic groups (Anglin et al., 2015).

The current study extends this work by investigating the role of dissociation in psychotic experience (hallucination-proneness and delusional ideation) with a UK student sample, and using two measures of depersonalisation to address validity concerns.

\section{Hypotheses and research questions}

1. Dissociation will mediate the relationship between childhood maltreatment and hallucination-proneness.

2. Does dissociation mediate the relationship between childhood maltreatment and delusional ideation? 
3. Depersonalisation (one component of dissociation) will mediate the relationship between childhood maltreatment and hallucination-proneness.

\section{Method}

\section{Participants}

Two hundred undergraduate students of a population of approximately 16,000 from a UK university formed a convenience sample in exchange for course credits. Participants were selfselecting and the great majority were psychology undergraduates. Their ages ranged from 18 to 38 years $(M=19.96, S D=2.18)$. The sample included 165 females $(82.5 \%), 34$ males $(17 \%)$ and one individual who identified as 'other' $(0.5 \%)$. The majority identified themselves as 'British' (69\%) or 'Any other White background' (7.5\%). The most common ethnic minority was Indian $(4.5 \%)$.

\section{Design and data analysis plan}

The study used a cross-sectional, correlational design to test for mediation. Childhood maltreatment was the independent variable, and hallucination-proneness and delusional ideation were the dependent variables. Dissociation was the proposed mediator, which was divided into the constituent processes of depersonalisation (DP), absorption (AB) and dissociative amnesia (DAM). Meditational analyses were completed using the PROCESS macro for SPSS (Hayes, 2013). Direct and indirect effects were assessed using ordinary least squares (OLS) regressions. 
The significance of each indirect effect was tested following the Preacher and Hayes (2004) bootstrapping method, based on bias corrected and accelerated (BCa) 95\% confidence intervals.

\section{Measures}

\section{Child Abuse and Trauma Scale (CATS; Sanders \& Becker-Launsen, 1995).}

The CATS is a 38-item self-report scale of psychological maltreatment in childhood and adolescence. The measure yields three sub-scales: sexual abuse; punishment and physical abuse; neglect and degree of negativity. Kent and Waller (1998) proposed a fourth sub-scale of emotional abuse. Many items are highly sensitive, e.g. "Did your relationship with your parents ever involve a sexual experience?" Participants respond using a five-point scale $(0=$ never; 4=always). Total and sub-scale summed scores are divided by the number of items endorsed, giving final scores from $0-4$. The scale had adequate to excellent test-retest reliability $(r=.71-.91)$ and variable internal consistency $(\alpha=63-.90)$ in the original student sample, with excellent internal consistency in the current sample $(\alpha=.95)$.

\section{Launay-Slade Hallucination Scale-Revised (LSHS-R; Bentall and Slade, 1985).}

The LSHS-R is a 12-item measure of sub-clinical visual and auditory hallucinatory experience. Participants rate applicability of items (e.g. 'I have been troubled by hearing voices in my head') using a five-point scale ( $4=$ certainly applies to me; $0=$ certainly does not apply to me), yielding a total score of $0-48$. The LSHS-R had good test-retest reliability $(r=.84)$ and adequate internal 
consistency $(\alpha=.79)$ in the original student sample, and this was good in the current sample $(\alpha=.87)$.

\section{The Dissociative Experiences Scale-II (DES-II; Bernstein-Carlson \& Putnam,} 1993).

This 28-item measure of dissociative experiences yields three main factors: dissociative amnesia, depersonalisation-derealisation and absorption. Participants rate applicability of items (e.g. 'Some people find that they sometimes sit staring off into space, thinking of nothing, and are not aware of the passage of time') using a yes/no format together with percentage of time that the person has the experience. Total scores are prorated. The DES-II had good internal consistency $(\alpha=.83)$ and test-retest reliability $(r=.84)$ in the original general population sample (BersteinCarlson \& Putnam, 1993). Wright and Loftus (1999) reported excellent internal consistency in a student sample $(\alpha=.93)$ and this was replicated in the present study $(\alpha=.95)$.

\section{Cambridge Depersonalisation Scale (CDS; Sierra \& Berrios, 2000).}

The 29-item CDS was designed to measure depersonalisation. Items (e.g. 'I have the feeling of being outside my body') are rated for frequency (from $0=$ never, to $6=$ more than a week) and duration (from $1=a$ few seconds, to $4=a b o u t$ a day). Frequency and duration for each item are summed to give a total score. The CDS had good internal consistency $(\alpha=.89)$ and excellent splithalf reliability $(r=.92)$ in the original clinical sample (Sierra \& Berrios, 2000), and excellent internal consistency in the current student sample $(\alpha=.97)$. Given limited psychometric data for 
the CDS to date, we also tested for convergent validity with the DES-II, which was adequate for the current sample $(r=.74, p<.001)$.

\section{1-Item Peters et al. Delusions Inventory (PDI; Peters, Joseph, Day, \&}

\section{Garety, 2004).}

The 21-item PDI measures delusional ideation in the general population. Participants respond to statements (e.g. 'Do you ever feel as if there is a conspiracy against you?') using a yes/no format. Items endorsed are rated for distress, preoccupation and conviction, using five-point scales (from $1=$ not distressing at all/hardly ever think about it/don't believe it's true, to 5=very distressing/think about it all the time/believe it is absolutely true). The PDI yields four sub-scale scores: number of items endorsed (0-21), and distress, preoccupation and conviction (0-105). A grand total provides a global measure of delusional ideation, calculated by summing the subscale scores (0-336). The authors report good internal consistency $(\alpha=.82)$ and adequate to good test-retest reliability (yes/no: $r=.78$, distress: $r=.81$; preoccupation: $r=.81$; conviction: $r=.78$ ) in the original general population sample (Peters et al., 2004). Jones and Fernyhough (2007) report adequate internal consistency in their student sample $(\alpha=.77)$, and this was excellent in the current sample $(\alpha=.91)$.

\section{Procedure}

University ethics committee approval was granted. All potential participants were provided with information about the study and consented prior to completion of the questionnaires. Participants were advised of the sensitive nature of some questions, and reminded that they could withdraw at 
any time. Questionnaires were completed online. At the end of the study, an online mood repair task was used to alleviate any distress, and participants were fully debriefed, again online. The debrief included a description of the study rationale and aims, the email address of the primary researcher, and a list of support services in the event that anyone required further support.

\section{Results}

\section{Descriptive statistics and correlational analyses}

Table 1 gives descriptive statistics and inter-correlations.

\section{Table 1 about here}

Parametric assumptions were not met, so two-tailed Spearman's rho correlations were used to examine relationships between measures. The main variables correlated in line with the mediational models. Total CATS scores were positively associated with dissociation, hallucination-proneness and delusional ideation. Each of the CATS sub-scales was positively associated with dissociation and hallucination-proneness. All but the sexual abuse sub-scale were positively associated with delusional ideation. Dissociation, hallucination-proneness, and delusional ideation all correlated with each other. 


\section{Mediational analyses}

We tested the significance of the indirect effect of dissociation on hallucination-proneness and delusional ideation, using simple-mediational analyses (Figures 1 and 2). No covariates were included in the analyses.

Figure 1 about here

Figure 2 about here

These show a significant direct effect of childhood maltreatment on hallucination-proneness with a regression coefficient of $2.92(95 \%$ CI .42, 5.43), and on delusional ideation with a regression coefficient of $10.90(95 \%$ CI 3.65, 18.15). The total indirect effect of childhood maltreatment via dissociation was significant for both hallucination-proneness and delusional ideation, with regression coefficients of 3.94 (95\% CI 2.15, 6.37) and 10.75 (95\% CI 5.87, 17.56) respectively. This suggests that dissociation plays a mediating role in the relationship between childhood maltreatment and psychotic-type experience.

We then tested the significance of the total indirect effect of childhood maltreatment via the three dissociative processes (dissociative amnesia, depersonalisation and absorption) on hallucinationproneness, and the specific indirect effects of each, using multiple-mediation (Figure 3).

Figure 3 about here

Depersonalisation, measured by the DES-II depersonalisation subscale, and by the CDS, did not mediate the relationship between childhood maltreatment and hallucination-proneness. Similarly, 
dissociative amnesia did not mediate this relationship. However, absorption did mediate the relationship.

Finally, we completed an exploratory mediation analysis of the total indirect effect of childhood maltreatment via the three dissociative processes on delusional ideation (Figure 4).

Figure 4 about here

Depersonalisation did not mediate the relationship between childhood maltreatment and delusional-ideation. Dissociative amnesia negatively mediated this relationship. Absorption also mediated the relationship. Table 2 summarises the results of these analyses.

Table 2 about here

The total proportion of the variance in psychotic-type experience accounted for by these models was large for both hallucination-proneness and delusional ideation.

\section{Discussion}

This study used a cross-sectional design to assess whether dissociation, and specific dissociative processes, mediate the relationship between childhood maltreatment and psychotic-type experience in a non-clinical sample. Dissociation mediated both hallucination-proneness and delusional ideation. Depersonalisation (assessed using two separate measures) did not mediate hallucination-proneness or delusional ideation. Absorption mediated hallucination-proneness; dissociative amnesia (negatively) and absorption mediated delusional ideation. 
There is growing evidence that early adversity is associated with psychotic experience in the clinical population (Bentall et al., 2014; Longden, Sampson \& Read, 2015; Perona-Garcelan et al., 2012; Varese, Barkus and Bentall, 2012). This study adds to the emerging evidence for a similar relationship in the non-clinical population (cf DeRosse, Nitzburg, Kompancaril \& Malhotra, 2014; Perona-Garcelan et al., 2014), with a strength of association comparable to that found by Varese and colleagues (2012) in their meta-analysis of clinical level psychosis.

Taken together, these results indicate that a history of maltreatment is a risk factor for psychosis across the general to clinical populations (cf Johns \& van Os, 2001). In terms of specific forms of harm, sexual, emotional and physical abuse, and neglect were all associated with hallucination-proneness. All forms but sexual abuse were associated with delusional ideation. This was an unexpected result given previous research that has identified sexual abuse as a risk factor for sub-clinical delusions (e.g. Lataster et al., 2006). This may be due to a reluctance to report highly sensitive information in our study, and requires replication before drawing conclusions.

Beyond the association between early adversity and adult psychotic-type experience, we were interested in understanding the mechanisms of these relationships. As predicted, dissociation mediated the relationship between childhood maltreatment and hallucination-proneness. This is consistent with similar results in clinical groups and initial research with non-clinical participants (Varese, Barkus \& Bentall, 2012; Perona-Garcelan et al., 2012; Perona-Garcelan et al., 2014). Together, these results support the information-processing theory proposed by Holmes et al. (2005), who argue that peri-traumatic dissociation disrupts information processing, resulting in 
poorly encoded autobiographical representations, which may then be re-experienced as intrusions of traumatic content, i.e. hallucinations. In our exploratory mediational analysis, dissociation also mediated the relationship between childhood maltreatment and delusional ideation. This is a novel finding, and consistent with the account proposed by Moskowitz and colleagues (2009) in which delusional beliefs are conceptualised as attempts to explain anomalous experience including dissociation. For example, an individual with high trait dissociation following childhood maltreatment might experience feelings of unreality and form the belief that they are permanently dreaming or disconnected from others. This may serve the purpose of protecting the person from fully experiencing abuse at the time, and from fully experiencing the meaning of the abuse for their sense of self and relationships with others, later. Future studies might usefully focus on individuals' attributions for dissociative experience following a history of early maltreatment.

We then examined the impact of particular forms of dissociation using multiple-mediation. Depersonalisation, measured using two separate scales, did not mediate hallucination-proneness. This was unexpected and inconsistent with previous findings (Perona-Garcelan et al., 2012; Perona-Garcelan et al., 2014). Although the results were approaching significance, it may be that non-pathological depersonalisation does not have such detrimental effects on informationprocessing for adverse events as in clinical groups (cf. Ruiter, Elzinga \& Phaf, 2006). Replication studies are required to clarify the role of depersonalisation in non-clinical groups before drawing conclusions. 
Interestingly, the present study found that absorption mediated both hallucination-proneness and delusional ideation. This replicates and extends earlier findings (Perona-Garcelan et al., 2014), and indicates that delusional ideation as well as hallucination-proneness is likely to be affected by absorption in non-clinical groups. Absorption is a form of intensively focused attention in which a person becomes immersed in his or her mental imagery. DES II items include re-living events as if occurring now, and being distracted from the present and 'lost' in fantasy or TV to the degree that these events seem to be actually happening. Being immersed in mental imagery to this degree has clear parallels with hallucinatory experience. DES II items also include being unable to determine the veracity of memories. This confusion between reality and imagination could result in constructed explanations and attributions that would be judged by others to be delusional.

We also found that that dissociative amnesia had a negative mediating effect on delusional ideation; more severe childhood maltreatment was associated with lower delusional ideation, mediated by dissociative amnesia. This is an unusual finding and should be treated cautiously prior to replication. Kennerley (2009), following Holmes et al. (2005), emphasises distinct functions of different types of dissociation. 'Tuning in' (absorption) may result in re-living of intrusive peri-traumatic information in the form of flashbacks and hallucinations. 'Tuning out' (dissociative amnesia) may result in a loss of access to traumatic information in memory. This may explain the current findings; absorption would be expected to have a positive mediating effect, while dissociative amnesia would be expected to have a negative mediating effect, as was found. 
The study is limited by a reliance on self-report measures and a cross-sectional design that precludes assumptions about causality. While the CATS is a retrospective assessment dependent on people's memories for adverse events and willingness to report these accurately, there is evidence that reliability for abuse disclosures of people with psychosis is good (Fisher et al., 2011). Our cross-sectional design means that we cannot assume dissociation mediates psychotictype experience. The inverse may also be true - that hallucination-proneness and delusional ideation increase risk of dissociation. This could be tested with a longitudinal design. Finally, the sample was predominantly made up of White British women. The findings may not be generalisable to the young adult population more widely.

Notwithstanding these limitations, the study contributes to growing evidence that dissociation may mediate the relationship between early maltreatment and hallucination-proneness across general and clinical populations, and adds to the more equivocal research on delusional ideation. Theoretical accounts to date have focused on the role of detachment or depersonalisation in psychosis. Our results suggest that absorption may be more relevant. Replication studies are now needed to establish whether this is case, investigating the effects of specific dissociative processes on information-processing of adverse events, and the relationships with psychotic experience. In line with Holmes et al. (2005), it is likely that dissociation interferes with the encoding of peri-traumatic information in particular ways. For some people, poorly integrated memories of early adversity, or explanations of these, may intrude into conscious awareness as psychotic-type experience. If true, it stands to reason that dissociation might serve as a maintenance factor for such psychotic experiences. This has important implications for clinical 
practice - interventions targeting dissociation might reduce psychotic symptoms and thereby alleviate linked distress.

Clarity about the role of dissociative processes in the relationship between childhood maltreatment and psychosis will inform our understanding of psychosis across the population, as well as clinical practice. Wider implications include the need to train staff how to ask people about early maltreatment (Read et al., 2007) and respond effectively to disclosures (Ashmore et al., 2015; Bateman et al., 2013). In this way we might change the culture of healthcare services so that we routinely recognise the impact of early adversity on our mental health, and respond skilfully in our therapeutic work.

\section{References}

American Psychiatric Association. (2013). Diagnostic and statistical manual of mental disorders (5th ed.). Washington, DC: Author.

Beavan, V., Read, J., \& Cartwright, C. (2011). The prevalence of voice-hearers in the general population: A literature review. Journal of Mental Health, 20(3), 281-292.

Bebbington, P. E., McBride, O., Steel, C., Kuipers, E., Radovanovič, M., Brugha, T., ... \& Freeman, D. (2013). The structure of paranoia in the general population. The British Journal of Psychiatry, 202(6), 419-427.

Bentall, R. P., de Sousa, P., Varese, F., Wickham, S., Sitko, K., Haarmans, M., \& Read, J. (2014). From adversity to psychosis: Pathways and mechanisms from specific adversities to specific symptoms. Social Psychiatry and Psychiatric Epidemiology, 49(7), 1011-1022. 
Bentall, R.P., \& Slade, P. (1985). Reliability of a scale measuring disposition towards hallucination: a brief report. Personality and Individual Differences, 6(4), 527-529.

Bentall, R.P., Wickham, S., Shevlin, M., \& Varese, F. (2012). Do specific early-life adversities lead to specific symptoms of psychosis? A study from the 2007 the Adult Psychiatric Morbidity Survey. Schizophrenia Bulletin, 38(4), 734-740.

Bernstein-Carlson, E., \& Putnam, F.W. (1993). An update on the Dissociative Experiences Scale. Dissociation, 6(1), 16-27.

Dalenberg, C.J. \& Paulson, K. (2010). The case for the study of 'normal' dissociation processes. In P. F. Dell \& J. A. O'Neil (Eds.), Dissociation and the dissociative disorders: DSM-V and beyond (pp. 145-154). London: Routledge.

Daniel, B., Wassell, S., \& Gilligan, R. (2010). Child Development for Child Care and Protection Workers (2nd ed.). London: Jessica Kingsley Publishers.

DeRosse, P., Nitzburg, G.C., Kompancaril, B., \& Malhotra, A.K. (2014). The relation between childhood maltreatment and psychosis in patients with schizophrenia and non-psychiatric controls. Schizophrenia Research, 155(1-3), 66-71.

De Ruiter, M.B., Alzinga, B.M., \& Phaf, R.H. (2006). Dissociation: cognitive capacity or dysfunction? Journal of Trauma and Dissociation, 7(4), 115-134.

Ehlers, A., \& Clark, D.M. (2000). A cognitive model of posttraumatic stress disorder. Behaviour Research and Therapy, 38, 319-345. 
Freeman, D. (2007). Suspicious minds: The psychology of persecutory delusions. Clinical Psychology Review, 27(4), 425-457.

Hayes, A.F. (2013). An introduction to mediation, moderation, and conditional process analysis: A regression-based approach. New York: Guilford Press.

Holmes, E.A., Brown, R.J., Mansell, W., Pasco, F., Hunter, E.C.M., Frasquilho, F., \& Oakley, D.A. (2005). Are there two qualitatively distinct forms of dissociation? A review and some clinical implications. Clinical Psychology Review, 25(1), 1-23.

Jones, S.R. \& Fernyhough, C. (2007). Reliability of factorial structure of the Peters et al. Delusions Inventory (PDI-21). Personality and Individual Differences, 43: 647-656.

Johns, L.C., \& van Os, J. (2001). The continuity of psychotic experiences in the general population. Clinical Psychology Review, 21(8), 1125-1141.

Kennedy, F. \& Kennerley, H. (2013) The development of our understanding of dissociation. In F. Kennedy, H. Kennerley and D. Pearson (Eds.), Cognitive behavioural approaches to the understanding and treatment of dissociation (pp. 1-16). London: Routledge.

Kennerley, H. (2009). Cognitive therapy for post-traumatic dissociation. In Grey, N. A. (Ed.), Casebook of cognitive therapy for traumatic stress reactions (pp. 93-110). London: Routledge.

Kent, A., \& Waller, G. (1998). The impact of childhood emotional abuse: An extension of the Child Abuse and Trauma Scale. Child Abuse and Neglect, 22(5), 393-399. 
Kessler, R.C., McLaughlin, K.A., Green, J.G., Gruber, M.J., Sampson, N.A., Zaslavsky, A.M., ... Williams, D.R. (2010). Childhood adversities and adult psychopathology in the WHO World Mental Health Surveys. British Journal of Psychiatry, 197, 378-385.

Lataster, T., van Os, J., Drukker, M., Henquet, C., Feron, F., Gunther, N., \& Myin-Germeys, I, (2006). Childhood victimisation and developmental expression of non-clinical delusional ideation and hallucinatory experiences. Social Psychiatry and Psychiatric Epidemiology, 41(6), 423-428.

Molnar, B. E., Buka, S. L., \& Kessler, R. C. (2001). Child sexual abuse and subsequent psychopathology: Results from the National Comorbidity Survey. American Journal of Public Health, 91(5), 753-760.

Moskowitz, A., Read, J., Farrelly, S., Rudegeair, T., \& Williams, O. (2009). Are psychotic symptoms traumatic in origin and dissociative in kind? In P. Dell \& J. O’Neil (Eds.), Dissociation and the dissociative disorders: DSM-V and beyond (pp. 322-351). New York: Routledge.

Moscowitz, A., \& Heim, G. (2011). Eugen Bleuler's 'Dementia Praecox or the Group of Schizophrenias' (1911): A Centenary Appreciation and Reconsideration. Schizophrenia Bulletin $37(3), 471-479$.

Perona-Garcelán, S., Carrascoso- López, F., García-Montes, J.M., Ductor-Recuerda, M.J., Jiménez, A.M.L., Vallina-Fernández, O., ... Gómez-Gómez, M.T. (2012). Dissociative experiences as mediators between childhood trauma and auditory hallucinations. Journal of Traumatic Stress, 25(3), 323-329. 
Perona-Garcelan, S., Garcia-Montes, J., Rodriguez-Testal, J., Lopez-Jimenez, A., Ruiz-Veguilla, M., \& Ductor-Recuerda, M., ... Perez-Alvarez, M. (2014). Relationship between childhood trauma, mindfulness, and dissociation in subjects with and without hallucination proneness. Journal of Trauma \& Dissociation, 15(1), 35-51.

Peters, E., Joseph, S., Day, S., \& Garety, P. (2004) Measuring delusional ideation: the 21-item Peters et al. Delusions Inventory (PDI). Schizophrenia Bulletin, 30(4), 1005-1022.

Read, J., Agar, K., Argyle, N., \& Aderhold, V. (2003) Sexual and physical abuse during childhood and adulthood as predictors of hallucinations, delusions and thought disorder. Journal of Psychology \& Psychotherapy, 76(1), 1-22.

Read, J., Hammersley, P., \& Rudegeair, T. (2007). Why, when and how to ask about childhood abuse. Advances in Psychiatric Treatment, 13(2), 101-110.

Sanders B., \& Becker-Launsen E (1995). The measurement of psychological maltreatment: early data on the Child Abuse and Trauma Scale. Child Abuse and Neglect, 19(3), 315-323.

Sierra, M., \& Berrios, G.E. (2000). The Cambridge Depersonalization Scale: A new instrument for the measurement of depersonalization. Psychiatry Research, 93(2), 153-164.

Van der Hart, O., \& Horst, R. (1989). The dissociation theory of Pierre Janet. Journal of Traumatic Stress, 2(4), 397-412.

Varese, F., Barkus, E., \& Bentall, R.P. (2012). Dissociation mediates the relationship between childhood trauma and hallucination-proneness. Psychological Medicine, 42(5), 1025-1036. 
Varese, F., Smeets, F., Drukker, M., Lieverse, R., Lataster, T., Viechtbauer, W., ... Bentall, R.P. (2012). Childhood adversities increase the risk of psychosis: A meta-analysis of patient-control, prospective- and cross-sectional cohort studies. Schizophrenia Bulletin, 38(4), 661-671.

Wright, D.B., \& Loftus, E.F. (1999). Measuring dissociation: Comparison of alternative forms of the dissociative experiences scale. American Journal of Psychology, 112(4), 497-519. 
Table 1: Descriptive statistics and inter-correlations

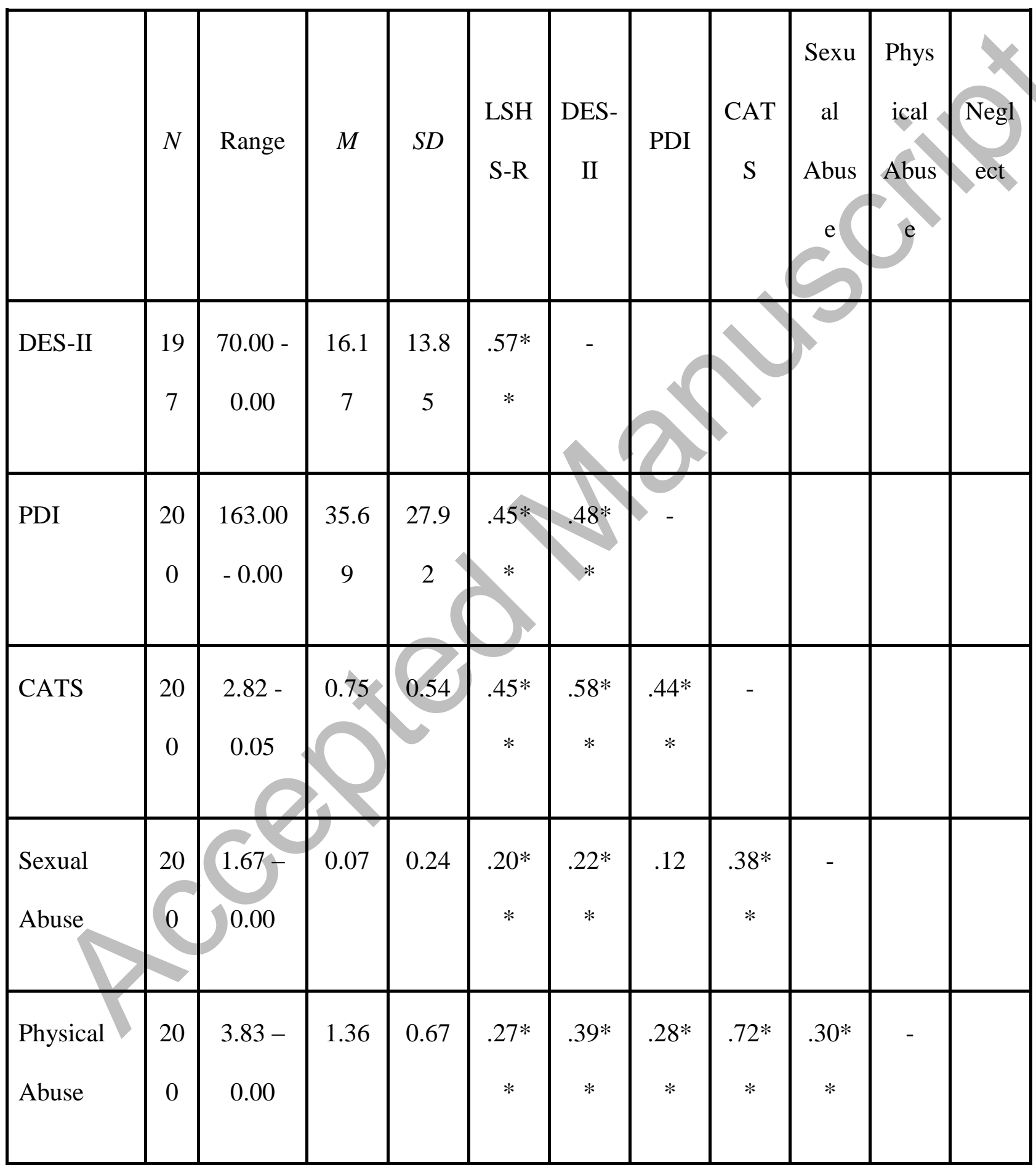




\begin{tabular}{|l|c|c|c|c|c|c|c|c|c|c|c|}
\hline Neglect & 20 & $3.07-$ & 0.78 & 0.69 & $.44 *$ & $.57 *$ & $.46^{*}$ & $.91^{*}$ & $.31 *$ & $.49 *$ & - \\
0 & 0.00 & & & $*$ & $*$ & $*$ & $*$ & $*$ & $*$ & \\
\hline Emotional & 20 & $3.71-$ & 0.98 & 0.76 & $.43 *$ & $.45^{*}$ & $.36 *$ & $.85 *$ & $.35^{*}$ & $.51^{*}$ & $.75 *$ \\
Abuse & 0 & 0.00 & & & $*$ & $*$ & $*$ & $*$ & $*$ & $*$ & $*$ \\
\hline
\end{tabular}

Note. LSHS-R = Launay-Slade Hallucination Scale-Revised, DES-II = Dissociative Experiences Scale-II, PDI = Peters Delusions Inventory, CATS = Child Abuse and Trauma Scale.

$* * p<.01$ 
Table 2: Summary of simple and multiple-mediation analyses

\begin{tabular}{|c|c|c|c|c|c|}
\hline $\begin{array}{l}\text { Dependent } \\
\text { variable }\end{array}$ & $\begin{array}{l}\text { Mediating } \\
\text { variable }\end{array}$ & Direct effect & $\begin{array}{l}\text { Indirect } \\
\text { effect }\end{array}$ & Total effect & $\begin{array}{c}\text { Variance } \\
\left(\mathrm{R}^{2}\right)\end{array}$ \\
\hline $\begin{array}{l}\text { Hallucination- } \\
\text { proneness }\end{array}$ & Dissociation & $\begin{array}{c}2.92(0.42 \text { to } \\
5.43)^{*}\end{array}$ & $\begin{array}{c}3.94(2.15 \text { to } \\
6.37)^{*}\end{array}$ & & \\
\hline$(N=196)$ & DAM & $\begin{array}{c}1.64(-0.86 \\
\text { to } 4.14)\end{array}$ & $\begin{array}{c}-1.32(-3.20 \\
\text { to } 0.03)\end{array}$ & $\begin{array}{c}5.22(3.44 \text { to } \\
7.53)^{*}\end{array}$ & 0.34 \\
\hline & $\mathrm{AB}$ & & 3.45 (2.00 to & & \\
\hline & & & $\begin{array}{c}0.97(-1.23 \\
\text { to } 3.46)\end{array}$ & & \\
\hline & CDS & & $\begin{array}{c}2.12(-0.04 \\
\text { to } 4.62)\end{array}$ & & \\
\hline $\begin{array}{l}\text { Delusional } \\
\text { ideation }\end{array}$ & Dissociation & $\begin{array}{l}10.90(3.65 \\
\text { to } 18.15)^{*}\end{array}$ & $\begin{array}{l}10.75(5.87 \\
\text { to } 17.56)^{*}\end{array}$ & & 0.29 \\
\hline
\end{tabular}




\begin{tabular}{|l|c|c|c|c|c|}
\hline$(N=197)$ & DAM & $\begin{array}{c}7.45(0.16 \text { to } \\
14.73)^{*}\end{array}$ & $\begin{array}{c}-3.68(-9.46 \\
\text { to }-0.03)^{*}\end{array}$ & $\begin{array}{l}14.20(8.54 \\
\text { to } 20.96)^{*}\end{array}$ & 0.34 \\
\hline & AB & & $\begin{array}{c}7.18(2.87 \text { to } \\
13.33)^{*}\end{array}$ & & \\
\hline & DP & & $6.32(-0.70$ & & \\
& & & to 17.88$)$ & & \\
\hline & CDS & & $4.38(-2.97$ & & \\
& & & to 12.96$)$ & & \\
\hline
\end{tabular}

Note. $D A M=$ Dissociative Amnesia $; A B=$ Absorption $; D P=$ Depersonalisation $; C D S=$ Cambridge Depersonalisation Scale. Values are non-standardised B coefficients using 5000 bootstrap replications.

$*_{p}=<.05$ 
Figure 1: Simple-mediation model for hallucination-proneness

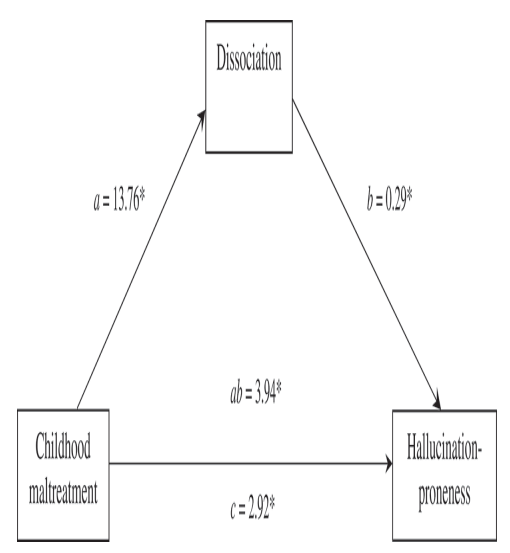

Note. Values are unstandardized B coefficients. $a=$ effect of childhood maltreatment on dissociation; $b=$ effect of dissociation on hallucination-proneness; $c=$ direct effect of maltreatment on hallucination-proneness; $a b=$ indirect effect.

${ }^{*} p<.05 \longrightarrow$ denotes significant effects $\longrightarrow$ denotes non-significant effects 
Figure 2: Simple-mediation model for delusional ideation

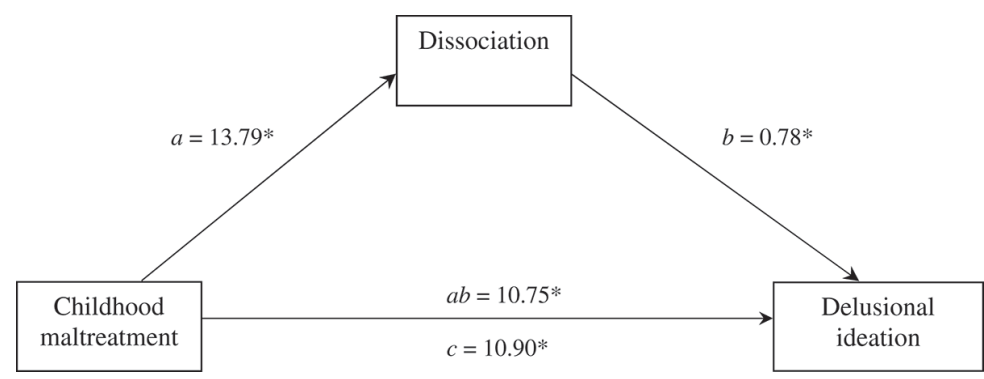

Note. Values are unstandardized B coefficients. $a=$ effect of childhood maltreatment on dissociation; $b=$ effect of dissociation on delusional ideation; $c=$ direct effect of maltreatment on delusional ideation; $a b=$ indirect effect.

$\longrightarrow$ denotes significant effects $\quad \longrightarrow$ denotes non-significant effects 
Figure 3: Multiple-mediation model for hallucination-proneness

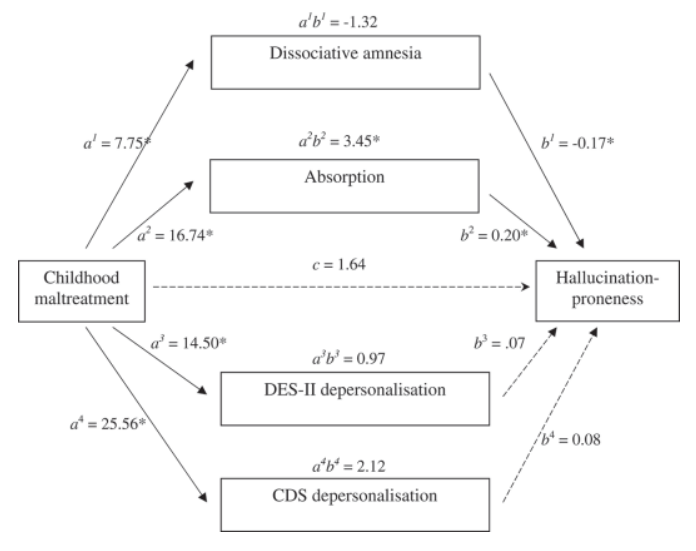

Note. Values are unstandardized B coefficients. $a^{l}=$ effect of childhood maltreatment on DAM; $a^{2}=$ effect of childhood maltreatment on $A B ; a^{3}=$ effect of childhood maltreatment on DP; $a^{4}=$ effect of childhood maltreatment on CDS; $b^{1}=$ effect of DAM on hallucination-proneness; $b^{2}=$ effect of $A B$ on hallucination-proneness; $b^{3}=$ effect of DP on hallucination-proneness; $b^{4}=$ effect of CDS on hallucination-proneness; $a^{1} b^{1}=$ indirect effect of DAM; $a^{2} b^{2}=$ indirect effect of $A B ; a^{3} b^{3}=$ indirect effect of DP; $a^{4} b^{4}=$ indirect effect of $C D S ; c=$ direct effect .

$\longrightarrow$ denotes significant effects

$----\rightarrow$ denotes non-significant effects

$* p<.05$ 
Figure 4: Multiple-mediation model for delusional ideation

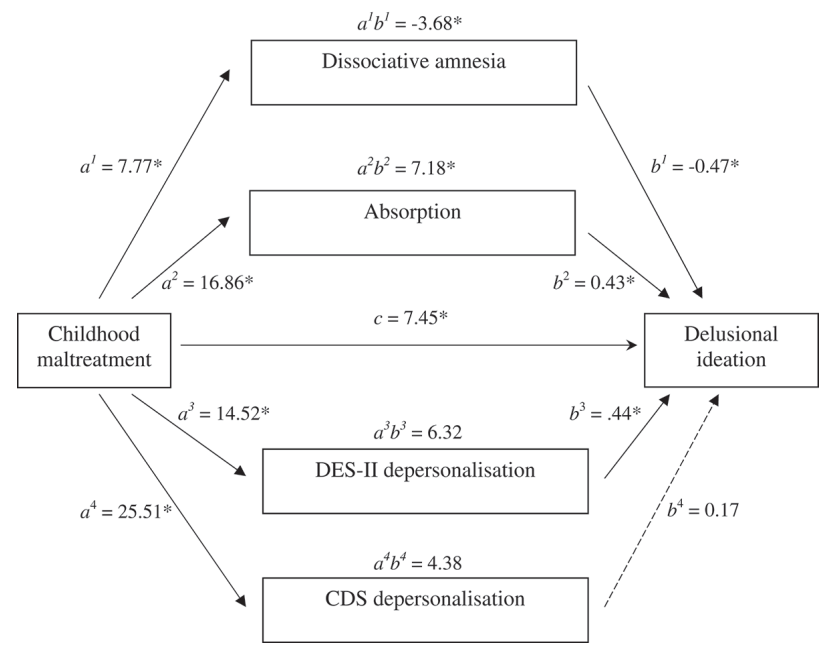

Note. Values are unstandardized B coefficients. $a^{1}=$ effect of childhood maltreatment on DAM; $a^{2}=$ effect of childhood maltreatment on $A B ; a^{3}=$ effect of childhood maltreatment on DP; $a^{4}=$ effect of childhood maltreatment on CDS; $b^{1}=$ effect of DAM on delusional ideation; $b^{2}=$ effect of $A B$ on delusional ideation; $b^{3}=$ effect of $D P$ on delusional ideation; $b^{4}=$ effect of $C D S$ on delusional ideation; $a^{1} b^{1}=$ indirect effect of DAM; $a^{2} b^{2}=$ indirect effect of $A B ; a^{3} b^{3}=$ indirect effect of DP; $a^{4} b^{4}=$ indirect effect of $C D S ; c=$ direct effect

$\longrightarrow$ denotes significant effects $\stackrel{---\longrightarrow}{\longrightarrow}$ denotes non-significant effects

$* p<.05$ 